\title{
Limited proteolysis of pyranose 2-oxidase results in a stable and active complex
}

\author{
Tanzila Islam $^{1}$, Catherine Booker ${ }^{1}$, Dmitri Tolkatchev ${ }^{1}$, Su Ha ${ }^{\text {Corresp., } 1}$, Alla S Kostyukova ${ }^{\text {Corresp. } 1}$ \\ ${ }^{1}$ Voiland School of Chemical Engineering and Bioengineering, Washington State University, Pullman, WA, United States \\ Corresponding Authors: Su Ha, Alla S Kostyukova \\ Email address: su.ha@wsu.edu, alla.kostyukova@wsu.edu
}

Glucose oxidating enzymes have a tremendous potential for various energy, healthcare and environmental sensing applications. In this work, we studied the effect of reducing the size of pyranose 2-oxidase (POx) on stability and enzymatic activity of proteolyzed POx. Limited proteolysis of the POx was performed using trypsin to remove flexible structural regions without significant damage to the overall conformation and catalytic activity of the enzyme. Enzymatic activities of the modified and wild-type POx were measured by colorimetric coupled reaction assay and compared. The enzymatic activity of the modified POx showed $90 \%$ activity compared to the wild-type POx. This result indicates that reducing the size of the protein can be done without losing enzymatic activity and such enzymes potentially could provide a larger gain in electrochemical activity compared with wild-type enzymes. 
1 Limited Proteolysis of Pyranose 2-Oxidase Results in a Stable and Active Complex

2

\author{
Tanzila Islam, Catherine Booker, Dmitri Tolkatchev, Su Ha*, Alla S. Kostyukova*
}

Voiland School of Chemical Engineering and Bioengineering, Washington State University, Pullman, WA 99164-6515.

*corresponding authors

Addresses for correspondence:

The Gene and Linda Voiland School of Chemical Engineering and Bioengineering, 1505 Stadium Way, Room 105, P.O. Box 646515, Washington State University, Pullman, WA 991646515, E-mail: suha@wsu.edu.

The Gene and Linda Voiland School of Chemical Engineering and Bioengineering, 1505 Stadium Way, Room 105, P.O. Box 646515, Washington State University, Pullman, WA 991646515. E-mail: alla.kostyukova@wsu.edu.

\begin{abstract}
Glucose oxidating enzymes have a tremendous potential for various energy, healthcare and environmental sensing applications. In this work, we studied the effect of reducing the size of pyranose 2-oxidase (POx) on stability and enzymatic activity of proteolyzed POx. Limited proteolysis of the POx was performed using trypsin to remove flexible structural regions without significant damage to the overall conformation and catalytic activity of the enzyme. Enzymatic activities of the modified and wild-type POx were measured by colorimetric coupled reaction assay and compared. The enzymatic activity of the modified POx showed $90 \%$ activity compared to the wild-type POx. This result indicates that reducing the size of the protein can be done without losing enzymatic activity and such enzymes potentially could provide a larger gain in electrochemical activity compared with wild-type enzymes.
\end{abstract}

\title{
Introduction
}

The combination of proteins and nanomaterials to produce various functional enzyme electrodes is important for both understanding the fundamental protein-nanomaterial interactions and the development of high performance bioelectronic devices ${ }^{1}$. An establishment of an efficient electrochemical communication between the active site of protein and the electrode surfaces, while maintaining a long-term protein stability, is a critical step for developments of any practical bioelectronics devices (e.g., biosensors ${ }^{2}$, biofuel cells ${ }^{3}$, neuronsemiconductor hybrid systems for dynamic memory ${ }^{1}$, etc.). To achieve these goals, previous investigators have created functional enzyme electrodes by immobilizing the enzyme on the external surface of nanomaterials ${ }^{4-10}$; by entrapping it in sol-gel ${ }^{6,11-13}$ or polymers ${ }^{3,14-22}$, by using bulk composite ${ }^{6}$; by chemically modifying structures of enzymes ${ }^{23-27}$. However, either a poor electrochemical communication of these immobilized enzymes to electrodes or their short lifetime hinders the development of practical bioelectronic devices ${ }^{3,28,29}$.

Effective direct, non-mediated electrical wiring of enzyme on electrodes remains a challenging task ${ }^{30,31}$. Newly developed approaches that can enhance direct electron transfer include improving the surface properties of the electrode by introducing highly conductive nanoparticles and controlling enzyme orientation by changing surface charge properties ${ }^{32-34}$. Several recent studies developed modified enzyme supports for better wiring by surface grafting of

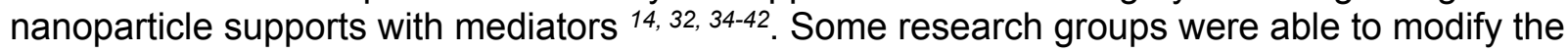
surface charge properties of enzymes to control the orientation of their adsorption on electrode

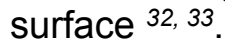


50

51

52

53

54

55

56

57

58

59

60

61

62

63

64

65

66

67

68

69

70

71

72

73

74

75

76

77

78

79

80

81

82

83

84

85

86

87

88

89

90

91

92

93

94

95

96

97

98

99

Glucose oxidase (GOx) is one of the most frequently used enzymes for glucose based biofuel cells and biosensors due to its high and selective reactivity towards glucose oxidation, well-known crystal structure and easy availability. Recently, another flavin-dependent enzyme, pyranose 2-oxidase (POx), has gained increased attention due to its attractive structural features ${ }^{43,44}$. POx catalyzes the oxidation of D-glucose at $C 2$ position to yield 2-dehydro Dglucose while producing electrons that can be utilized in either power generation for biofuel cells or glucose detection for the biosensors ${ }^{45-47}$. Unlike GOx, the POx protein is not surrounded by electrochemically nonconductive glycosylation layer in its native state. This structural characteristic offers better mass transport of glucose and better potential for efficient electron transfer from the active site to the electrode. Therefore, POx is considered a good candidate for biofuel cell and biosensor applications.

POx is a homotetrameric enzyme, which contains one flavin adenine dinucleotide (FAD) per subunit 48,49 . POx tetramer structure has a hydrodynamic radius of $6.2 \mathrm{~nm}$ where each of the $4 \mathrm{FAD} / \mathrm{FADH}_{2}$ centers is buried $\sim 1.4 \mathrm{~nm}$ below the enzyme surface ${ }^{49,50}$. In our current study, we aimed to remove its exposed flexible polypeptide regions. The main idea was to decrease the POx dimensions in such a way that the protein core remains intact. We chose POx from Phanerochaete chrysosporium because it is the most stable POx compared to POxs from other organisms ${ }^{51}$. The exposed flexible regions were removed from the surface of POx by limited proteolysis. We demonstrated that the POx structure minimization by limited trypsinolysis does not eliminate its enzymatic activity and the tryptic fragments still maintain a stable quaternary structure.

\section{Materials \& Methods}

POx recombinant plasmid construct

The DNA sequence encoding POx from Phanerochaete chrysosporium (GenBank: AAS93628.1) was optimized for Escherichia coli expression using the online tool OPTIMIZER ${ }^{52}$ The optimized sequence was synthesized and cloned into a pET-21b(+) vector between Ndel and Xhol restriction sites at GenScript (Piscataway, NJ).

Expression and purification of $P O x$

The recombinant $\mathrm{pET}-21 \mathrm{~b}(+)$ plasmid with a confirmed $\mathrm{POx}$ insert sequence was used to transform competent BL21(DE3) E. coli cells (Life Technologies). A freshly transformed E. coli colony was used to inoculate $5 \mathrm{ml}$ of LB medium supplied with $100 \mu \mathrm{g} / \mathrm{ml}$ ampicillin. The culture was grown in an incubator shaker at $37^{\circ} \mathrm{C}$ for 4 hours at $250 \mathrm{rpm}$, then it was transferred into $500 \mathrm{ml}$ of the same growth medium and shaken at $37^{\circ} \mathrm{C}$ and $220 \mathrm{rpm}$. Once the optical density of the culture reached $\mathrm{OD}_{600}=0.5$, the temperature was lowered to $25^{\circ} \mathrm{C}$, and after 1 hour protein expression was induced by the addition of $0.1 \mathrm{mM}$ isopropyl $\beta-\mathrm{D}-1$ -

thiogalactopyranoside (IPTG). The induced cells were incubated at $25^{\circ} \mathrm{C}$ and $220 \mathrm{rpm}$ overnight and harvested by centrifugation at $4000 \mathrm{~g}$ for 20 minutes. Harvested cells were resuspended in $30 \mathrm{ml}$ of $50 \mathrm{mM}$ sodium phosphate buffer at pH 7.8 with $300 \mathrm{mM} \mathrm{NaCl}, 10 \mathrm{mM}$ imidazole and $0.1 \mathrm{mM}$ PMSF supplied with an EDTA-free complete Protease Inhibitor Cocktail tablet (Roche, Mannheim, Germany). The cells were disrupted by sonication on ice for a total of 10 minutes. Cell lysate was cleared of cell debris by centrifugation at $16000 \mathrm{rpm}$ (Beckman JA-17 rotor) for 30 minutes at $4^{\circ} \mathrm{C}$ and mixed with $15 \mathrm{ml}$ of Qiagen Ni-NTA agarose. The suspension was shaken at $4^{\circ} \mathrm{C}$ for 1 hour, loaded onto a column and washed with 6 bed volumes of $50 \mathrm{mM}$ sodium phosphate buffer at $\mathrm{pH} 7.8$ with $300 \mathrm{mM} \mathrm{NaCl}, 10 \mathrm{mM}$ imidazole, $0.1 \mathrm{mM} \mathrm{PMSF}$ at $4^{\circ} \mathrm{C}$. The resin was washed (1) with $50 \mathrm{mM}$ sodium phosphate buffer at pH 7.8 containing $300 \mathrm{mM}$ $\mathrm{NaCl}$ and $50 \mathrm{mM}$ imidazole, and (2) with $50 \mathrm{mM}$ sodium phosphate buffer at $\mathrm{pH} 7.8$ containing $300 \mathrm{mM} \mathrm{NaCl}$ and $100 \mathrm{mM}$ imidazole. The POx protein was eluted with $50 \mathrm{mM}$ sodium phosphate buffer at pH 7.8 with $300 \mathrm{mM} \mathrm{NaCl}$ and $250 \mathrm{mM}$ imidazole and was kept either in ice or flash-frozen in liquid nitrogen with $10 \%$ glycerol and stored at $-80^{\circ} \mathrm{C}$ until use. For further 
100

101

102

103

104

105

106

107

108

109

110

111

112

113

114

115

116

117

118

119

120

121

122

123

124

125

126

127

128

129

130

131

132

133

134

135

136

137

138

139

140

141

142

143

144

145

146

147

148

149

experimentations, stock POx was dialyzed against $50 \mathrm{mM}$ sodium phosphate buffer at $\mathrm{pH} 7$ with $500 \mathrm{mM} \mathrm{NaCl}$.

Protein concentration was determined using bicinchoninic acid assay (Thermo Scientific, Waltham, MA) according to the manufacturer's protocol. Molecular mass calculations were done using ExPASy ProtParam tool ${ }^{53}$. The calculated molecular mass of full-length POx was 72,198 $\mathrm{Da}$ and the molecular mass of proteolyzed POx was 66,529 Da, considering that fragments ii, iv and vi (Figure 1c) remain intact after limited proteolysis.

Molecular Dynamics Simulations (MDS)

The crystal structure of POx (PDB ID: 4mig, chains A, B, C and D) was used for molecular dynamics simulations. Loop polypeptide fragments between peptide bonds that were assumed to be cleaved by trypsin were removed from the chain A in silico, and a pdb file for proteolyzed POx was generated using UCSF CHIMERA $1.9{ }^{54}$. Simulations of the proteolyzed POx tetramer were conducted using AMBER 1155 . Hydrogen atoms were first added and the peptide was then placed in a simulated box of TIP3P water molecules with a $10 \AA$ minimal distance from the outermost side chains to the edge of the box. The charge of the protein was neutralized by adding $\mathrm{Na}^{+}$ions in the protein-water simulated box. The system was energy-minimized to overcome the effects of steric overlap between atoms. The motion of each peptide was simulated as a function of time using the SHAKE algorithm ${ }^{56}$ with a time step of 2 femtoseconds. The simulations were run at $300 \mathrm{~K}$ for 80 nanoseconds in order to reach steady states. Structural comparison was done using UCSF CHIMERA 1.9.

\section{Limited proteolysis}

To remove the flexible unstructured regions of POx structure, limited proteolysis was performed using trypsin. Trypsin is a highly specific serine protease, which cleaves peptide chains at the carbonyl side of lysine and arginine. The limited proteolysis was done in $50 \mathrm{mM}$ sodium phosphate buffer at $\mathrm{pH} 7$, containing $500 \mathrm{mM} \mathrm{NaCl}$ at room temperature. POx to trypsin mass ratio of 50:1 was used. At several time points, $10 \mu$ aliquots were removed, mixed with the sample buffer (2x Laemmli buffer composition: $0.125 \mathrm{M}$ Tris- $\mathrm{HCl}, 20 \%$ Glycerol, $4 \%$ SDS, $0.004 \%$ bromophenol blue, $10 \%$ 2-mercaptoethanol) for analysis and boiled to terminate trypsinolysis. The results were analyzed by sodium dodecyl sulfate polyacrylamide gel electrophoresis (SDS-PAGE). Molecular masses of protein bands were calculated using Image Lab software (BioRad).

Purification of POx proteolytic fragments

To prepare large quantities of proteolytic fragments for further enzyme testing, trypsinolysis was terminated by adding $1 \mathrm{mM}$ Pefabloc in 5.5 hours. Proteolytic fragments were purified either by Fast Protein Liquid Chromatography (FPLC) using a QFF anion exchange column (for CV experiments) or Size Exclusion Chromatography using a PD-10 desalting column (GE Healthcare Life Sciences, Pittsburgh, PA) (for cross-linking and CD experiments). For FPLC based purification, we used $20 \mathrm{mM}$ Tris and $1 \mathrm{mM}$ DTT at $\mathrm{pH} 8.5$ with $0-1 \mathrm{M} \mathrm{NaCl}$ gradient to elute samples. POx fragments were eluted from $0.30 \mathrm{M}$ to $0.36 \mathrm{M} \mathrm{NaCl}$ concentration range. For desalting column based purification, we used $50 \mathrm{mM}$ sodium phosphate buffer at $\mathrm{pH} 7$, containing $500 \mathrm{mM} \mathrm{NaCl}$.

\section{POx cross-linking with glutaraldehyde}

For cross-linking experiments, we used full-length POx and proteolyzed POx $(0.415 \mathrm{mg} / \mathrm{ml})$ in $50 \mathrm{mM}$ sodium phosphate buffer at $\mathrm{pH}$ 7, containing $500 \mathrm{mM} \mathrm{NaCl}$. Full-length POx was treated with $0.02 \%(\mathrm{v} / \mathrm{v})$ glutaraldehyde at room temperature and $10 \mu \mathrm{l}$ aliquots were removed at 10 and 60 minutes time points. Crosslinking reaction was stopped by adding $10 \mu$ of the sample buffer for SDS-PAGE. POx fragments were treated with glutaraldehyde (GA) $(0.05 \%$ and 0.10 $\%(\mathrm{v} / \mathrm{v}))$ at room temperature and $10 \mu \mathrm{l}$ aliquots were removed at 30 and 60 minutes time points. Crosslinking reactions were stopped by adding $10 \mu \mathrm{l}$ sample buffer for SDS/PAGE.

Size exclusion chromatography 
150

151

152

153

154

155

156

157

158

159

160

161

162

163

164

165

166

167

168

169

170

171

172

173

174

175

176

177

178

179

180

181

182

183

184

185

186

187

188

189

190

191

192

193

194

195

196

197

198

199

For size exclusion chromatography of POx, we used Superdex 75 10/300 GL column (GE Healthcare, Pittsburgh, PA). $200 \mu \mathrm{l}(\sim 0.4 \mathrm{mg} / \mathrm{ml})$ of a sample was loaded for each protein. For eluting the protein samples, we used $50 \mathrm{mM}$ phosphate buffer at $\mathrm{pH} 7$ containing $150 \mathrm{mM} \mathrm{NaCl}$ at flow rate of $0.5 \mathrm{ml} / \mathrm{min}$.

Circular dichroism (CD) measurements

CD spectra of $0.1 \mathrm{mg} / \mathrm{ml}$ full length POx and proteolyzed POx in $12.5 \mathrm{mM}$ sodium phosphate buffer at $\mathrm{pH} 7$ with $125 \mathrm{mM} \mathrm{NaCl}$ were recorded at $20^{\circ} \mathrm{C}$ from 195 to $250 \mathrm{~nm}$ at 0.5 nm intervals, on an Aviv CD spectrometer Model 400 (Aviv Biomedical Inc., Lakewood, NJ). Hellma Analytics (Plainview, NY) quartz cuvettes with $1 \mathrm{~mm}$ path length were used for CD measurements.

Enzyme activity assay

Color reagent for activity assay was prepared by mixing $20.3 \mathrm{mg}$ 4-aminoantipyrine, $9.5 \mathrm{mg}$ Phenol, $1 \mathrm{mg}$ Peroxidase, $10 \mathrm{ml}$ Tris-HCl buffer $(0.1 \mathrm{M}, \mathrm{pH} 7)$ in a light protected tube. For enzyme activity assay, $800 \mu \mathrm{l}$ deionized water, $500 \mu \mathrm{l}$ Tris- $\mathrm{HCl}(0.1 \mathrm{M}, \mathrm{pH} 7), 100 \mu \mathrm{l}$ color reagent, $50 \mu \mathrm{l}$ of $1 \mathrm{M}$ glucose, $50 \mu \mathrm{l} 0.02 \mathrm{mg} / \mathrm{ml}$ POx sample were added and mixed thoroughly. During the reaction, quinoneimine dye was produced which absorbs light at $500 \mathrm{~nm}$. The rate of production of quinonimine dye is directly proportional to the enzymatic oxidation of glucose. The reactions associated in the experiment are:

D-Glucose $+\mathrm{O}_{2} \rightarrow$ 2-Dehydro-D-glucose $+\mathrm{H}_{2} \mathrm{O}_{2}$

$2 \mathrm{H}_{2} \mathrm{O}_{2}+4$-Aminoantipyrine + Phenol $\rightarrow$ Quinoneimine dye $+4 \mathrm{H}_{2} \mathrm{O}$

The absorbance of the reaction mixture was recorded immediately at $500 \mathrm{~nm}$ for 4 minutes. We performed 10 enzyme activity assay measurements for three separately obtained samples of proteolyzed POx and reported the mean and standard deviation as error bars in the corresponding figure.

Statistical analysis

We ran two tailed statistical t-test between the two groups of enzyme activity results (10 experiments per replicates $\times 3$ replicates each $=30$ data points for each) of wild-type and modified POx. The test result gave the $p$-value of 0.0079 . We considered $p$-value below 0.05 as statistically significant difference.

\footnotetext{
Results

In silico removal of exposed flexible regions in POx had no significant effect on POx structure.

Initial inspection of the POx amino acid sequence and its three-dimensional structure (pdb\#4mig) demonstrated presence of several exposed disordered regions. Disordered flexible regions occupy more space than ordered ones, so we hypothesize that by removing them we will be able to reduce distance between the surface of the protein and its active site. We chose limited proteolysis by trypsin to remove exposed flexible regions of POx with the purpose of overall structural reduction. Trypsin cleaves peptide chains at the carbonyl side of lysine $(\mathrm{K})$ and arginine (R). Exposed disorder and flexible regions in proteins are typically the most susceptible to proteolytic cleavage. Removal of the exposed flexible regions will cut the protein primary sequence into several fragments (Figure 1c), but given the high stability of the intact POx, the secondary and tertiary structural components (e.g., alpha helices, beta sheets, hydrogen bonds, disulfide bonds) may still maintain the overall globular protein conformation.

To predict the effects of trypsinolysis on POx conformation, we analyzed the crystal structure of POx shown in Figure 1. We identified five exposed disordered regions that are available in the POx structure. The regions are Met1-Pro13 (N-terminal residue), Met55-Gly70, Leu307-Ser319, His345- Pro374, and Arg618-His629 (C-terminal residue), all highlighted in gray in Figure 1c. As trypsin is highly specific in cleaving after Arg and Lys residues, we identified potential trypsin cleavage sites within these exposed disordered regions (Figure 1c).
} 
200 Figure 1c also shows the sequences of POx tryptic fragments that we predicted to be produced

201

202

203

204

205

206

207

208

209

210

211

212

213

214

215

216

217

218

219

220

221

222

223

224

225

226

227

228

229

230

231

232

233

234

235

236

237

238

239

240

241

242

243

244

245

246

247

248

249

250 after limited proteolysis. Upon treatment with trypsin, two exposed flexible fragments, residues Gly57-Arg63 and Gly361-Arg367 (iii-magenta and v-black, respectively), together with the N- (iorange) and C- (vii-purple) terminal flexible fragments were expected to be removed from the POx structure. Although the removal of these four exposed flexible regions will create gaps within the POx structure, we expected the other three fragments (ii- blue, iv-green and vi-red) to keep most of the non-covalent contacts existing in the intact protein. Therefore, we assumed that these three fragments would remain bound together in a compact globular structure and maintain the surrounding of the central FAD molecule in a way appropriate for efficient enzymatic catalysis.

To mimic the trypsinolysis in silico, we removed the chosen regions (region i, iii, $\mathrm{v}$, vii in Figure 1c) from the wild-type POx. Then, we performed molecular dynamic simulation for the modified POx tetramer molecules to predict the effect of trypsinolysis on the modified POx conformation. The final simulated structure of the modified POx showed very small overall backbone shifts with respect to the wild-type POx (Figure 2a). These shifts had a root mean square deviation over $\mathrm{C}-\alpha$ atoms (rmsd) of $1.26 \AA$, which is comparable to the rmsd calculated for the wild-type POx with respect to a homologue of POx from different organism Trametes multicolor, which is $1.07 \AA$ (between $\mathrm{C}-\alpha$ atoms). Therefore, we did not expect to significantly alter the structure of the POx active center and thus the functionality of POx.

We analyzed the positions of the residues that are important for the catalysis of glucose oxidation. The residues from His553 to Asn596 (Figure 2c) are active site residues and residues from Arg457 to Glu467 (Figure 2f) are dynamic substrate recognition loops that are important for the catalysis and substrate recognition ${ }^{57}$. We compared these two important regions in the wildtype and modified POx structures and found no significant differences. There were slight backbone shifts with rmsd over $\mathrm{C}-\alpha$ atoms of $0.754 \AA$ and $2.48 \AA$ respectively, and helices formation in regions Thr564-Lys566 and Val465-Glu467 (shown in gray circles in Figure 2c and $2 f$ respectively, rmsd calculated between $C-\alpha$ atoms for these circled regions are $0.633 \AA$ and $3.45 \AA$ respectively). All these differences are far away from the FAD (yellow) and substrate binding sites (cyan). For this reason, we expected that these changes will not have significant effect on enzyme functionality. In addition to that, His158 and Thr160 are reported important in catalysis and binding to the FAD group ${ }^{51}$. Figure $2 \mathrm{e}$ shows His158 residue and Figure $2 \mathrm{~b}$ shows the Thr160 residue where wild-type (blue) and modified (brown) proteins are superimposed to compare their side chain conformations. There is no significant difference other than small backbone shift in His158 (rmsd over C- $\alpha$ atoms $=0.827 \AA)$ and Thr160 (rmsd over $\mathrm{C}-\alpha$ atoms $=1.133 \AA$ ) residues.

We also compared positions of the POx residues that are reported to participate in tetramer formation. A long oligomerization arm comprising residues lle105 to Asn134 helps to form POx homotetramer ${ }^{57}$. Figure $2 \mathrm{~d}$ shows superimposed oligomerization arms of wild-type (blue) and modified (brown) POx structure. We observed a small backbone shift with the rmsd of $1.82 \AA$ between $\mathrm{C}-\alpha$ atoms that may not be significant enough to alter the tetramer formation. These MDS results suggested that removal of disordered regions should not significantly affect the active center or formation of a tetramer and therefore should not affect the enzyme functionality.

Limited proteolysis of $\mathrm{POx}$ resulted in formation of several fragments.

Based on our prediction, limited proteolysis by trypsin will result in formation of seven fragments with theoretical molecular masses of fragment (i) through (vii): 1.127, 4.907, 0.725, $33.154,0.618,28.503,1.589 \mathrm{kDa}$, respectively (Figure 1c), three of which (fragments ii, iv and vi) will maintain a globular polypeptide structure, whereas the rest (fragments $\mathrm{i}$, iii, $v$ and vii) will be separated and exist as unbound and unstructured polypeptides in solution.

To find conditions and time for removal of flexible regions, trypsin was added to POx in $1: 50 \mathrm{w} / \mathrm{w}$ ratio and proteolysis was stopped in 3, 10, 30 and 60 minutes using protease inhibitor pefabloc. These are the typical time range used for limited proteolysis of proteins ${ }^{58}$. Within the

Peer] Mat. Sci. reviewing PDF | (MATSCI-2019:08:40593:1:1:NEW 8 Apr 2020) 
251 first three minutes, a band of $\sim 65 \mathrm{kDa}$ appeared corresponding to a $\sim 5 \mathrm{kDa}$ decrease in the

252

253

254

255

256

257

258

259

260

261

262

263

264 POx molecular mass (Figure 3a, lane 3). By the 60-minute time point, further proteolysis of 65 $\mathrm{kDa}$ fragment resulted in the formation of two major bands with molecular masses of $34 \mathrm{kDa}$ and $27 \mathrm{kDa}$ and a minor band of $32 \mathrm{kDa}$ (Figure $3 \mathrm{a}$, lane 6). At this point we performed an enzyme functionality assay and found that the enzyme was still highly active.

Next, we decided to increase the time of proteolysis until the $65 \mathrm{kDa}$ band disappears. For that, limited trypsinolysis was repeated and stopped at 4, 5, 5.5, 6, 6.5 and 7 hours. After 5 hours of treatment, most of the $65 \mathrm{kDa}$ band disappeared and the bands with the molecular masses 32 and 27 became the major ones, while the band with the MW of $34 \mathrm{kDa}$ became a minor band. This mixture of proteolytic fragments was very stable and did not undergo any further digestion for up to 7 hours (Figure 3b). Also, the reaction mixture was tested for POx functionality and it was found highly active.

Theoretically predicted molecular masses of tryptic fragments matched with actual molecular masses.

Comparing molecular masses of the obtained fragments with the predicted molecular weights (Figure 1c) and considering a $5 \%$ uncertainty in determining molecular mass of a protein using SDS-PAGE, we interpreted the $5 \mathrm{kDa}$ decrease in molecular mass appearing in the early stages of the trypsin digestion as originating from the removal of the $\mathrm{N}$ - and $\mathrm{C}$ terminal flexible regions of the protein (fragments $\mathrm{i}$ and vii). The predicted combined molecular mass of the $\mathrm{N}$ - and $\mathrm{C}$ - terminal regions is $2.716 \mathrm{kDa}$, which is less than the observed $5 \mathrm{kDa}$ mass decrease. However, our interpretation is consistent with the fact that the removal of the terminal regions should result in a single polypeptide and therefore a single band as in Figure $3 a$ (lane 3).

The $34 \mathrm{kDa}$ fragment corresponds to the predicted tryptic fragment-iv (green) flanked by the flexible region-iii (magenta) and the flexible region- $\mathrm{v}$ (black) (predicted combined molecular mass is $34.5 \mathrm{kDa}$ ). The $32 \mathrm{kDa}$ band corresponds to the predicted tryptic fragment-iv (green) (predicted molecular mass $33.2 \mathrm{kDa}$ ) after the flexible regions iii and $\mathrm{v}$ were removed from the $34 \mathrm{kDa}$ fragment. The $27 \mathrm{kDa}$ major band corresponds to the structured region vi (red) (theoretical molecular mass $28.5 \mathrm{kDa}$ ) (Figure 1c). Fragments with molecular masses smaller than $5 \mathrm{kDa}$ typically cannot be seen in $12 \%$ SDS-polyacrylamide gels due to their high mobility, fast diffusion and poor staining. Therefore, we did not expect to observe fragments that correspond to structured region ii, and flexible regions $\mathrm{i}$, iii, v, vii.

POx tryptic fragments form a tetramer.

Our MDS data indicated that removing the flexible regions by limited proteolysis should not affect the tetramer formation. Also during limited proteolysis, the oligomerization arm should not be affected by trypsin, since this segment is not exposed to the outer surface of POx. To verify experimentally that the tryptic fragments still form a tetramer, we cross-linked the protein by glutaraldehyde. Cross-linking by glutaraldehyde is often used to obtain preliminary information on quaternary structure of a protein ${ }^{59}$. When protein oligomers are treated with glutaraldehyde cross-linker, the polypeptide chains form inter-subunit covalent cross-links holding the chains together in a denaturing environment. These cross-linked chains can be further examined by SDS-PAGE and polypeptide chains interacting with each other can be identified. To perform this experiment, both full-length POx and POx fragments after 5.5 hours of trypsinolysis (denoted as proteolyzed POx thereafter) were crosslinked with different amounts of glutaraldehyde $(0.02 \%$, $0.05 \%, 0.1 \% \mathrm{v} / \mathrm{v}$ ) and analyzed by SDS-PAGE.

SDS-PAGE image in Figure 4 shows that, upon glutaraldehyde treatment, the proteolysed POx and the uncleaved full-length POx formed bands with molecular masses higher than a single polypeptide chain of the uncleaved POx. For the uncleaved POx, we observed bands with the molecular mass of 70,100, 126, 220 and a band above $250 \mathrm{kDa}$ (Figure 4a). Based on the sequence of POx predicting the molecular mass of a POx monomer as $70 \mathrm{kDa}$, the band $>250 \mathrm{kDa}$ corresponds to a cross-linked POx tetramer. Bands with lower molecular masses 
302

303

304

305

306

307

308

309

310

311

312

313

314

315

316

317

318

319

320

321

322

323

324

325

326

327

328

329

330

331

332

333

334

335

336

337

338

339

340

341

342

343

344

345

346

347

348

349

could represent cross-linked dimers and trimers. For the POx cleaved with trypsin, we observed bands with the highest molecular mass of above $250 \mathrm{kDa}$. Similar to the full-length POx, we assigned the band $>250 \mathrm{kDa}$ in Figure $4 \mathrm{~b}$ to a tetramer. The bands with lower molecular masses could correspond to intermediate cross-linked complexes of the proteolytic fragments.

We also performed size exclusion chromatography to estimate and compare the molecular sizes of the full-length and proteolyzed POx. Our results (Figure 5) showed that the two POx elution profile overlapped with each other confirming that they have similar molecular sizes that were not resolved on the column. The data we obtained from the glutaraldehyde treatment and the chromatography, therefore, show that after proteolysis the inter-subunit interactions in POx were not affected and the protein exists in solution in a tetrameric form.

Circular dichroism (CD) spectra analysis showed no increase in disorder after proteolysis.

Based on our MDS results, we expected that the proteolysis does not damage the enzyme structural conformation and therefore its functionality. Gel filtration data and the SDS-PAGE analysis of the proteolytic reaction mixture and the products of the glutaraldehyde treatment suggested that the limited trypsinolysis removed disordered regions of POx, while the globular structure of the POx core remained unaffected. Therefore, we expected that there would be no increase in the disordered secondary structure content of proteolyzed POx. CD spectroscopy is a powerful technique to study changes in the secondary structure content of any proteins. To prepare a sample of proteolyzed POx for CD analysis, we separated small cleaved fragments from the globular POx core by size exclusion chromatography. Figure 6 shows the CD spectra of the full-length and purified proteolyzed POx. There are no drastic changes in the spectrum, however, intersection of the spectrum of the proteolyzed POx with the $\mathrm{x}$-axis slightly shifted to higher wavelength compared to the spectrum of wild-type POx. This indicates the slight increase in ordered secondary structure content and suggests that the main core of cleaved POx maintained its native three-dimensional structure after removal of disordered regions during limited trypsinolysis.

Proteolyzed POx is functionally active.

Enzymatic activity is highly dependent on the structural conformation of its active site. Using CD, size exclusion chromatography and cross-linking we demonstrated that proteolysis did not affect the secondary and the quaternary structures of the enzyme, and therefore, most probably the tertiary structure, including the active site conformation, remains unchanged. In such case, the proteolyzed POx should still be functional. To test if removal of disordered flexible regions has an impact on its enzymatic activity, we measured the POx activity after proteolysis and compared it with the wild-type POx activity. The rate of enzymatic reaction was measured using a coupled reaction method that produces quinoneimine dye. Oxidation of glucose is directly coupled to the quinonimine dye production and the rate of change in quinoneimine dye concentration was a direct measure of the enzymatic activity. The activity test showed that the wild-type POx had specific activity of 39.5 $\pm 5.8 \Delta$ Absorbance $\cdot$ sec $^{-1} / \mu$ mole POx whereas modified POx had specific activity of $35.5 \pm 5.3 \Delta$ Absorbance $\sec ^{-1 /} \mu$ mole POx (the absorbance of the quinoneimine dye was measured at $500 \mathrm{~nm}$ ). Most of the enzyme activity $(\sim 90 \%)$ was retained after trypsin treatment (Figure 7$)$ confirming that there are no drastic changes in the active site conformation.

Ethics.

The study was carried out in accordance with the policies of the WSU Institutional Biosafety Committee (approval reference number 01131).

\section{Discussion}

Peer] Mat. Sci. reviewing PDF | (MATSCI-2019:08:40593:1:1:NEW 8 Apr 2020) 
One of the recent studies has performed deglycosylation of an enzyme named glucose oxidase $(\mathrm{GOx})$ to reduce the hydrodynamic diameter of the enzyme molecule and therefore the critical separation distance between active site and the surface ${ }^{60}$. As a result, the GOx active site was brought closer to its surface, and the electron transfer efficiency was significantly improved According to Marcus theory ${ }^{31}$, the kinetics of direct electron transfer between the active site of enzyme and the electrode surface is highly dependent on their separation distance. The probability for the electrons to "jump" from the active site of the enzyme to the electrode increases exponentially as the separation distance decreases. Therefore, for the proteins with deeply buried active sites, an approach involving protein size minimization can be a great solution to improve their electron transfer efficiency.

The difficulty with protein size minimization lies with the fact that enzymes are highly structurally organized molecules. Their three-dimensional (tertiary) globular structure is defined by their amino acid sequence, or primary structure, which evolved over considerable time. When enzyme primary structures are modified from their natural form, some important intramolecular interactions can be lost, which can change the overall conformation (tertiary structure) or even lead to a complete loss of structure rendering them unfolded. This will lead to the decrease or complete loss of their enzymatic activities. Consequently, the protein engineering effort aiming at the protein size minimization requires taking into consideration major forces holding the protein in its globular folded state and keeping the active site operational.

The removal of the flexible disordered regions of POx is an initial effort of the long-term goal of an enzyme structure minimization process to improve the electron transfer efficiency. In this study, we identified several exposed disordered regions that are available in the POx structure. Our molecular dynamic simulation results suggested that removal of these disordered regions from the wild-type POx should not significantly affect its active center or formation of its tetramer structure and therefore should not affect its functionality. The limited proteolysis of the POx was then performed using trypsin to remove the identified flexible structural regions. As our molecular dynamic simulation predicts, the experimental data obtained from the glutaraldehyde treatment and the chromatography show that after proteolysis the inter-subunit interactions in POx were not affected and the protein exists in solution in a tetrameric form. Circular dichroism spectra analysis also indicates that there are no decrease in ordered secondary structure content and confirms that the main core of cleaved POx maintained its native three-dimensional structure. The enzymatic activity of the modified POx showed only $10 \%$ reduced activity compared to the wild-type POx. Hence, we demonstrated that limited proteolysis removed the disordered regions from POx structure, while the protein core is structurally intact, stable and catalytically active. Enzyme structure minimization may be done not only using limited proteolysis but also by gene editing to remove secondary structure elements that may not affect active site formation. In this study, we removed not entire loops/termini but 34 residues only (5.4\% of total protein mass) due to trypsin specificity. In future studies, whole loops can be removed by changing them to short linkers (2-3 residue) by modifying the nucleotide sequence. This means that up to 70 residues can be removed and replaced by $6-9$ residues resulting in $10 \%$ decrease of the enzyme molecular mass. In addition, flexible loops occupy more space then ordered elements and the decrease in size may be even more than $10 \%$. MDS is a great tool to test results of such modifications. Modifications may decrease enzymatic activity, therefore the big challenge will be to ensure that any loss of enzymatic activity resulting from protein minimization is much smaller than the increase in the electron transfer efficiency.

\section{Acknowledgements}

We thank Natalia Moroz for helping in POx expression and Kyle Swain for helping in POx activity test. 
400

401

402

403

404

405

406

407

408

409

410

411

412

413

414

415

416

417

418

419

420

421

422

423

424

425

426

427

428

429

430

431

432

433

434

435

436

437

438

439

440

441

442

443

444

445

446

447

448

\section{References}

[1] Willner, I., and Katz, E. (2005) Bioelectronics: From Theory to Applications, Blackwell Science Publication, Oxford, England.

[2] Zhu, C., Yang, G., Li, H., Du, D., and Lin, Y. (2015) Electrochemical Sensors and Biosensors Based on Nanomaterials and Nanostructures, Analytical Chemistry 87, 230-249.

[3] Atanassov, P., Apblett, C., Banta, S., Brozik, S., Barton, S. C., Cooney, M. J., Liaw, B. Y., Mukerjee, S., and Minteer, S. D. (2007) Enzymatic Fuel Cells, The Electrochemical Society Interface 16, 28-31.

[4] Fischback, M. B., Youn, J. K., Zhao, X., Wang, P., Park, H. G., Chang, H. N., Kim, J., and Ha, S. (2006) Miniature Biofuel Cells with Improved Stability Under Continuous Operation, Electroanalysis 18, 2016-2022.

[5] Ivnitski, D., Atanassov, P., and Apblett, C. (2007) Direct Bioelectrocatalysis of PQQ-Dependent Glucose Dehydrogenase, Electroanalysis 19, 1562-1568.

[6] Kim, J., Jia, H., and Wang, P. (2006) Challenges in biocatalysis for enzyme-based biofuel cells, Biotechnology Advances 24, 296-308.

[7] Jia, H., Zhu, G., Vugrinovich, B., Kataphinan, W., Reneker, D. H., and Wang, P. (2002) Enzyme-Carrying Polymeric Nanofibers Prepared via Electrospinning for Use as Unique Biocatalysts, Biotechnology Progress 18, 1027-1032.

[8] Campbell, A. S., Jeong, Y. J., Geier, S. M., Koepsel, R. R., Russell, A. J., and Islam, M. F. (2015) Membrane/Mediator-Free Rechargeable Enzymatic Biofuel Cell Utilizing Graphene/Single-Wall Carbon Nanotube Cogel Electrodes, ACS Applied Materials \& Interfaces 7, 4056-4065.

[9] Scherbahn, V., Putze, M. T., Dietzel, B., Heinlein, T., Schneider, J. J., and Lisdat, F. (2014) Biofuel cells based on direct enzyme-electrode contacts using PQQ-dependent glucose dehydrogenase/bilirubin oxidase and modified carbon nanotube materials, Biosensors and Bioelectronics 61, 631-638.

[10] Prasad, K. P., Chen, Y., and Chen, P. (2014) Three-Dimensional Graphene-Carbon Nanotube Hybrid for High-Performance Enzymatic Biofuel Cells, ACS Applied Materials \& Interfaces 6, 3387-3393.

[11] Galarneau, A., Renard, G., Mureseanu, M., Tourrette, A., Biolley, C., Choi, M., Ryoo, R., Di Renzo, F., and Fajula, F. (2007) Synthesis of sponge mesoporous silicas from lecithin/dodecylamine mixed-micelles in ethanol/water media: A route towards efficient biocatalysts, Microporous and Mesoporous Materials 104, 103-114.

[12] Nogala, W., Burchardt, M., Opallo, M., Rogalski, J., and Wittstock, G. (2008) Scanning electrochemical microscopy study of laccase within a sol-gel processed silicate film, Bioelectrochemistry 72, 174-182.

[13] Lim, J., Malati, P., Bonet, F., and Dunn, B. (2007) Nanostructured Sol-Gel Electrodes for Biofuel Cells, Journal of The Electrochemical Society 154, A140-A145.

[14] Moore, C. M., Akers, N. L., Hill, A. D., Johnson, Z. C., and Minteer, S. D. (2004) Improving the Environment for Immobilized Dehydrogenase Enzymes by Modifying Nafion with Tetraalkylammonium Bromides, Biomacromolecules 5, 1241-1247.

[15] Mano, N., Mao, F., and Heller, A. (2003) Characteristics of a Miniature Compartment-less Glucose-O2 Biofuel Cell and Its Operation in a Living Plant, Journal of the American Chemical Society 125, 6588-6594.

[16] Mano, N., Mao, F., Shin, W., Chen, T., and Heller, A. (2003) A miniature biofuel cell operating at $0.78 \mathrm{~V}$, Chemical Communications, 518-519.

[17] Mao, F., Mano, N., and Heller, A. (2003) Long Tethers Binding Redox Centers to Polymer Backbones Enhance Electron Transport in Enzyme "Wiring" Hydrogels, Journal of the American Chemical Society 125, 4951-4957. 
449

450

451

452

453

454

455

456

457

458

459

460

461

462

463

464

465

466

467

468

469

470

471

472

473

474

475

476

477

478

479

480

481

482

483

484

485

486

487

488

489

490

491

492

493

494

495

496

497

498

[18] Akers, N. L., Moore, C. M., and Minteer, S. D. (2005) Development of alcohol/O2 biofuel cells using salt-extracted tetrabutylammonium bromide/Nafion membranes to immobilize dehydrogenase enzymes, Electrochimica Acta 50, 2521-2525.

[19] Xu, S., N. Pelster, L., Rasmussen, M., and Minteer, S. D. (2014) Anodic Bioelectrocatalysis: From Metabolic Pathways To Metabolons, In Enzymatic Fuel Cells, pp 53-79, John Wiley \& Sons, Inc.

[20] Aquino Neto, S., Hickey, D. P., Milton, R. D., De Andrade, A. R., and Minteer, S. D. (2015) High current density PQQ-dependent alcohol and aldehyde dehydrogenase bioanodes, Biosensors and Bioelectronics 72, 247-254.

[21] Aquino Neto, S., Almeida, T. S., Palma, L. M., Minteer, S. D., and de Andrade, A. R. (2014) Hybrid nanocatalysts containing enzymes and metallic nanoparticles for ethanol/O2 biofuel cell, Journal of Power Sources 259, 25-32.

[22] Gonzalez-Guerrero, M. J., Esquivel, J. P., Sanchez-Molas, D., Godignon, P., Munoz, F. X., del Campo, F. J., Giroud, F., Minteer, S. D., and Sabate, N. (2013) Membraneless glucose/O2 microfluidic enzymatic biofuel cell using pyrolyzed photoresist film electrodes, Lab on a Chip 13, 2972-2979.

[23] Willner, B., Katz, E., and Willner, I. (2006) Electrical contacting of redox proteins by nanotechnological means, Current Opinion in Biotechnology 17, 589-596.

[24] Zayats, M., Katz, E., Baron, R., and Willner, I. (2005) Reconstitution of Apo-Glucose Dehydrogenase on Pyrroloquinoline Quinone-Functionalized Au Nanoparticles Yields an Electrically Contacted Biocatalyst, Journal of the American Chemical Society 127, 1240012406.

[25] Katz, E., Sheeney-Haj-Ichia, L., and Willner, I. (2004) Electrical Contacting of Glucose Oxidase in a Redox-Active Rotaxane Configuration, Angewandte Chemie International Edition 43, 3292-3300.

[26] Katz, E., and Willner, I. (2003) A Biofuel Cell with Electrochemically Switchable and Tunable Power Output, Journal of the American Chemical Society 125, 6803-6813.

[27] Katz, E., and MacVittie, K. (2013) Implanted biofuel cells operating in vivo - methods, applications and perspectives - feature article, Energy \& Environmental Science 6, 27912803.

[28] Kang, C., Shin, H., Zhang, Y., and Heller, A. (2004) Deactivation of bilirubin oxidase by a product of the reaction of urate and $\mathrm{O} 2$, Bioelectrochemistry 65, 83-88.

[29] Ha, S., Wee, Y., and Kim, J. (2012) Nanobiocatalysis for Enzymatic Biofuel Cells, Topics in Catalysis 55, 1181-1200.

[30] Freire, R. S., Pessoa, C. A., Mello, L. D., and Kubota, L. T. (2003) Direct electron transfer: An approach for electrochemical biosensors with higher selectivity and sensitivity, Journal of the Brazilian Chemical Society 14, 230-243.

[31] Marcus, R. A., and Sutin, N. (1985) ELECTRON TRANSFERS IN CHEMISTRY AND BIOLOGY, Biochimica Et Biophysica Acta 811, 265-322.

[32] Lalaoui, N., Holzinger, M., Le Goff, A., and Cosnier, S. (2016) Diazonium Functionalisation of Carbon Nanotubes for Specific Orientation of Multicopper Oxidases: Controlling Electron Entry Points and Oxygen Diffusion to the Enzyme, Chemistry-a European Journal 22, 10494-10500.

[33] Lalaoui, N., Rousselot-Pailley, P., Robert, V., Mekmouche, Y., Villalonga, R., Holzinger, M., Cosnier, S., Tron, T., and Le Goff, A. (2016) Direct Electron Transfer between a SiteSpecific Pyrene-Modified Laccase and Carbon Nanotube/Gold Nanoparticle Supramolecular Assemblies for Bioelectrocatalytic Dioxygen Reduction, Acs Catalysis 6, 1894-1900.

[34] Gross, A. J., Chen, X. H., Giroud, F., Abreu, C., Le Goff, A., Holzinger, M., and Cosnier, S. (2017) A High Power Buckypaper Biofuel Cell: Exploiting 1,10-Phenanthroline-5,6-dione

Peer) Mat. Sci. reviewing PDF | (MATSCI-2019:08:40593:1:1:NEW 8 Apr 2020) 
499

500

501

502

503

504

505

506

507

508

509

510

511

512

513

514

515

516

517

518

519

520

521

522

523

524

525

526

527

528

529

530

531

532

533

534

535

536

537

538

539

540

541

542

543

544

545

546

547

548

with FAD-Dependent Dehydrogenase for Catalytically-Powerful Glucose Oxidation, Acs Catalysis 7, 4408-4416.

[35] Cosnier, S., Gross, A. J., Le Goff, A., and Holzinger, M. (2016) Recent advances on enzymatic glucose/oxygen and hydrogen/oxygen biofuel cells: Achievements and limitations, Journal of Power Sources 325, 252-263.

[36] Bourourou, M., Elouarzaki, K., Holzinger, M., Agnes, C., Le Goff, A., Reverdy-Bruas, N., Chaussy, D., Party, M., Maaref, A., and Cosnier, S. (2014) Freestanding redox buckypaper electrodes from multi-wall carbon nanotubes for bioelectrocatalytic oxygen reduction via mediated electron transfer, Chemical Science 5, 2885-2888.

[37] Gross, A. J., Chen, X. H., Giroud, F., Travelet, C., Borsali, R., and Cosnier, S. (2017) RedoxActive Glyconanoparticles as Electron Shuttles for Mediated Electron Transfer with Bilirubin Oxidase in Solution, Journal of the American Chemical Society 139, 1607616079.

[38] Rengaraj, S., Haddad, R., Lojou, E., Duraffourg, N., Holzinger, M., Le Goff, A., and Forge, V. (2017) Interprotein Electron Transfer between FeS-Protein Nanowires and OxygenTolerant NiFe Hydrogenase, Angew Chem Int Ed Engl 56, 7774-7778.

[39] Isikli, S., Lecea, M., Ribagorda, M., Carreno, M. C., and Diaz, R. (2014) Influence of quinone grafting via Friedel-Crafts reaction on carbon porous structure and supercapacitor performance, Carbon 66, 654-661.

[40] Klotzbach, T., Watt, M., Ansari, Y., and Minteer, S. D. (2006) Effects of hydrophobic modification of chitosan and Nafion on transport properties, ion-exchange capacities, and enzyme immobilization, Journal of Membrane Science 282, 276-283.

[41] Monsalve, K., Roger, M., Gutierrez-Sanchez, C., Ilbert, M., Nitsche, S., Byrne-Kodjabachian, D., Marchi, V., and Lojou, E. (2015) Hydrogen bioelectrooxidation on gold nanoparticlebased electrodes modified by Aquifex aeolicus hydrogenase: Application to hydrogen/oxygen enzymatic biofuel cells, Bioelectrochemistry 106, 47-55.

[42] Mazurenko, I., Monsalve, K., Rouhana, J., Parent, P., Laffon, C., Goff, A. L., Szunerits, S., Boukherroub, R., Giudici-Orticoni, M. T., Mano, N., and Lojou, E. (2016) How the Intricate Interactions between Carbon Nanotubes and Two Bilirubin Oxidases Control Direct and Mediated O2 Reduction, ACS Appl Mater Interfaces 8, 23074-23085.

[43] Kwon, K. Y., Kim, J. H., Youn, J., Jeon, C., Lee, J., Hyeon, T., Park, H. G., Chang, H. N., Kwon, Y., Ha, S., Jung, H. T., and Kim, J. (2014) Electrochemical Activity Studies of Glucose Oxidase (GOx)-Based and Pyranose Oxidase (POx)-Based Electrodes in Mesoporous Carbon: Toward Biosensor and Biofuel Cell Applications, Electroanalysis 26, 2075-2079.

[44] Tasca, F., Gorton, L., Kujawa, M., Patel, I., Harreither, W., Peterbauer, C. K., Ludwig, R., and Noll, G. (2010) Increasing the coulombic efficiency of glucose biofuel cell anodes by combination of redox enzymes, Biosens Bioelectron 25, 1710-1716.

[45] Schafer, A., Bieg, S., Huwig, A., Kohring, G., and Giffhorn, F. (1996) Purification by Immunoaffinity Chromatography, Characterization, and Structural Analysis of a Thermostable Pyranose Oxidase from the White Rot Fungus Phlebiopsis gigantea, Applied and Environmental Microbiology 62, 2586-2592.

[46] Wongnate, T., and Chaiyen, P. (2013) The substrate oxidation mechanism of pyranose 2oxidase and other related enzymes in the glucose-methanol-choline superfamily, FEBS $J$ 280, 3009-3027.

[47] Tan, T. C., Spadiut, O., Gandini, R., Haltrich, D., and Divne, C. (2014) Structural basis for binding of fluorinated glucose and galactose to Trametes multicolor pyranose 2-oxidase variants with improved galactose conversion, PLoS One 9, e86736.

[48] Hassan, N., Tan, T.-C., Spadiut, O., Pisanelli, I., Fusco, L., Haltrich, D., Peterbauer, C. K., and Divne, C. (2013) Crystal structures of Phanerochaete chrysosporium pyranose 2-

Peer] Mat. Sci. reviewing PDF | (MATSCI-2019:08:40593:1:1:NEW 8 Apr 2020) 
549

550

551

552

553

554

555

556

557

558

559

560

561

562

563

564

565

566

567

568

569

570

571

572

573

574

575

576

577

578

579

580

581

582

583

584

585

586

587

588

589

590

591 oxidase suggest that the $\mathrm{N}$-terminus acts as a propeptide that assists in homotetramer assembly(), FEBS Open Bio 3, 496-504.

[49] Danneel, H. J., Rössner, E., Zeeck, A., and Giffhorn, F. (1993) Purification and characterization of a pyranose oxidase from the basidiomycete Peniophora gigantea and chemical analyses of its reaction products, Eur J Biochem 214, 795-802.

[50] Martin Hallberg, B., Leitner, C., Haltrich, D., and Divne, C. (2004) Crystal Structure of the 270 kDa Homotetrameric Lignin-degrading Enzyme Pyranose 2-Oxidase, Journal of Molecular Biology 341, 781-796.

[51] Salaheddin, C., Takakura, Y., Tsunashima, M., Stranzinger, B., Spadiut, O., Yamabhai, M., Peterbauer, C. K., and Haltrich, D. (2010) Characterisation of recombinant pyranose oxidase from the cultivated mycorrhizal basidiomycete Lyophyllum shimeji (hon-shimeji), Microb Cell Fact 9, 57.

[52] Puigbò, P., Guzmán, E., Romeu, A., and Garcia-Vallvé, S. (2007) OPTIMIZER: a web server for optimizing the codon usage of DNA sequences, Nucleic Acids Res 35, W126-131.

[53] Gasteiger, E., Gattiker, A., Hoogland, C., Ivanyi, I., Appel, R. D., and Bairoch, A. (2003) ExPASy: The proteomics server for in-depth protein knowledge and analysis, Nucleic Acids Res 31, 3784-3788.

[54] Pettersen, E. F., Goddard, T. D., Huang, C. C., Couch, G. S., Greenblatt, D. M., Meng, E. C., and Ferrin, T. E. (2004) UCSF Chimera--a visualization system for exploratory research and analysis, Journal of computational chemistry 25, 1605-1612.

[55] Case, D. A., Darden, T. A., Cheatham III, T. E., Simmerling, C. L., Wang, J., Duke, R. E., Luo, R., Walker, R. C., Zhang, W., Merz, K. M., Roberts, B., Wang, B., Hayik, S., Roitberg, A., Seabra, G., Wong, K. F., Paesani, F., Vanicek, J., Liu, J., Wu, X., Brozell, S. R., Steinbrecher, T., Gohlke, H., Cai, Q., Ye, X., Wang, J., Hsieh, M.-J., Cui, G., Roe, D. R., Mathews, D. H., Seetin, M. G., Sagui, C., Babin, V., Luchko, T., Gusarov, S., Kovalenko, A., and Kollman, P. A. (2010) AMBER 11, (University of California, S. F., Ed.).

[56] Ryckaert, J.-P., Ciccotti, G., and Berendsen, H. (1977) Numerical integration of the cartesian equations of motion of a system with constraints: molecular dynamics of $n$-alkanes, Journal of Computational Physics 23, 15.

[57] Hassan, N., Tan, T. C., Spadiut, O., Pisanelli, I., Fusco, L., Haltrich, D., Peterbauer, C. K., and Divne, C. (2013) Crystal structures of Phanerochaete chrysosporium pyranose 2oxidase suggest that the $\mathrm{N}$-terminus acts as a propeptide that assists in homotetramer assembly, FEBS Open Bio 3, 496-504.

[58] Kostyukova, A., Maeda, K., Yamauchi, E., Krieger, I., and Maeda, Y. (2000) Domain structure of tropomodulin - Distinct properties of the $\mathrm{N}$-terminal and $\mathrm{C}$-terminal halves, European Journal of Biochemistry 267, 6470-6475.

[59] Fadouloglou, V. E., Kokkinidis, M., and Glykos, N. M. (2008) Determination of protein oligomerization state: two approaches based on glutaraldehyde crosslinking, Anal Biochem 373, 404-406.

[60] Courjean, O., Gao, F., and Mano, N. (2009) Deglycosylation of glucose oxidase for direct and efficient glucose electrooxidation on a glassy carbon electrode, Angew Chem Int Ed Engl 48, 5897-5899. 


\section{Figure 1}

Crystal structure of POx and prediction of proteolytic fragments from trypsin treatment.

(a) POx homo-tetramer with four subunits labeled as A, B, C and D (pdb:4mig); (b) two projections of the ribbon model of wild-type POx monomer with FAD shown in yellow. Circles and arrows show the locations of the exposed regions and the terminal flexible regions, respectively; (c) POx sequence shows exposed flexible regions and $\mathrm{N}$ - and $\mathrm{C}$ - terminal regions highlighted as gray. The $\operatorname{Arg}(R)$ and Lys $(K)$ representing potential cleavage sites are marked as red. Limited trypsinolysis is predicted to result in 7 fragments (separated by slash ' $l$ ' at the cleavage sites). Three proteolytic fragments (ii- blue, iv-green and vi-red) expected to remain together as the core of POx, while other fragments (iii-magenta, v-black i-orange and vii-purple) are expected to be removed. 


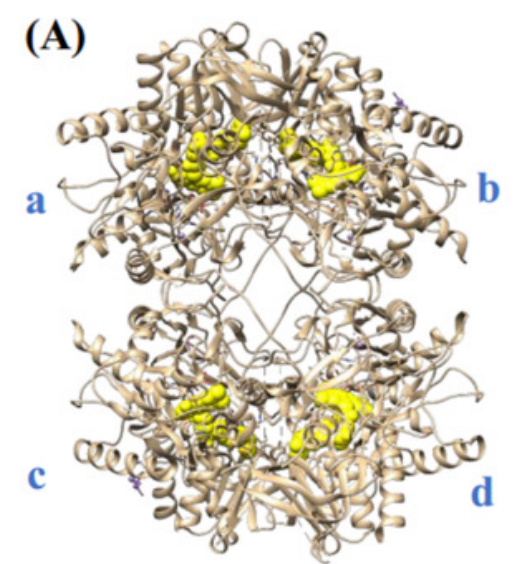

$$
\text { pdb\#4mig }
$$

(D)

$$
\text { (i) }
$$

(B)

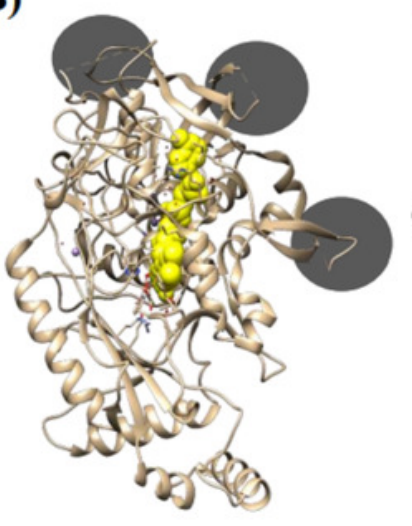

(C) $\mathrm{N}$ - terminus

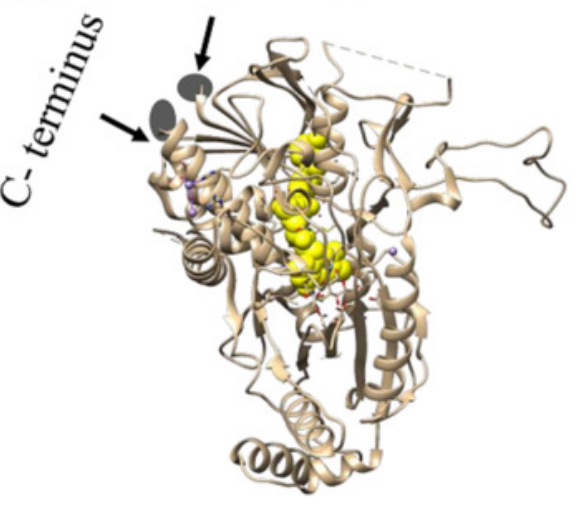

MFLDTTPFR/ADEPYDVFIAGSGPIGATFAKLCVDANLRVCMVEIGAADSFTSKPMK/GDPNAPR/SVQFGPGQVPIPGYHKK NEIEYQKDIDRFVNVIKGALSTCSIPTSNNHIATLDPSVVSNSLDKPFISLGKNPAQNPFVNLGAEAVTRGVGGMSTHWTCATPE FFAPADFNAPHRERPKLSTDAAEDARIWKDLYAQAKEIIGTSTTEFDHSIRHNLVLRKYNDIFOKENVIREFSPLPLACHRLTDPDY VEWHATDRILEELFTDPVKRGRFTLLTNHRCTKLVFKHYRPGEENEVDYALVEDLLPHMQNPGNPASVKKIYARSYVVACGAVA TAQVLANSHIPPDDVVIPFPGGEK/GSGGGER/DATIPTPLMPMLGKYITEOPMTFCOVVLDSSLMEVVRNPPWPGLDWWK EKVARHVEAFPNDPIPIPFRDPEPQVTIKFTEEHPWHVOIHRDAFSYGAVAENMDTRVIVDYRFFGYTEPQEANELVFOQHYR (vi)

DAYDMPQPTFKFTMSQDDRARARRMMDDMCNIALKIGGYLPGSEPQFMTPGLALHLAGTTRCGLDTQKTVGNTHCKVHN
(vii) FNNLYVGGNGVIETGFAANPTLTSICYAIRASNDIIAKFGR/HRGLEHHHHHH 


\section{Figure 2}

Molecular dynamic simulation results.

(a) Superimposed structures of monomers in simulated tetramers with (brown) and without modifications (blue); (b) Thr160 crucial for catalysis and binding to the co-factor; (c) active site residues comprising His553-Asn596 that participate in catalyzing the reaction of glucose oxidation ; '(d) oligomerization arm comprising residues Ile105-Asn134 that participate in POx tetramer formation, (e) His158 crucial for catalysis and binding to the co-factor; (f) dynamic substrate recognition loop' comprising residues Arg457-Glu467 important for substrate recognition and binding;. FAD is labeled yellow and substrate is labeled cyan. Gray circled regions in (c) and (f) show some structural differences of the modified POx compared to wild-type POx. 


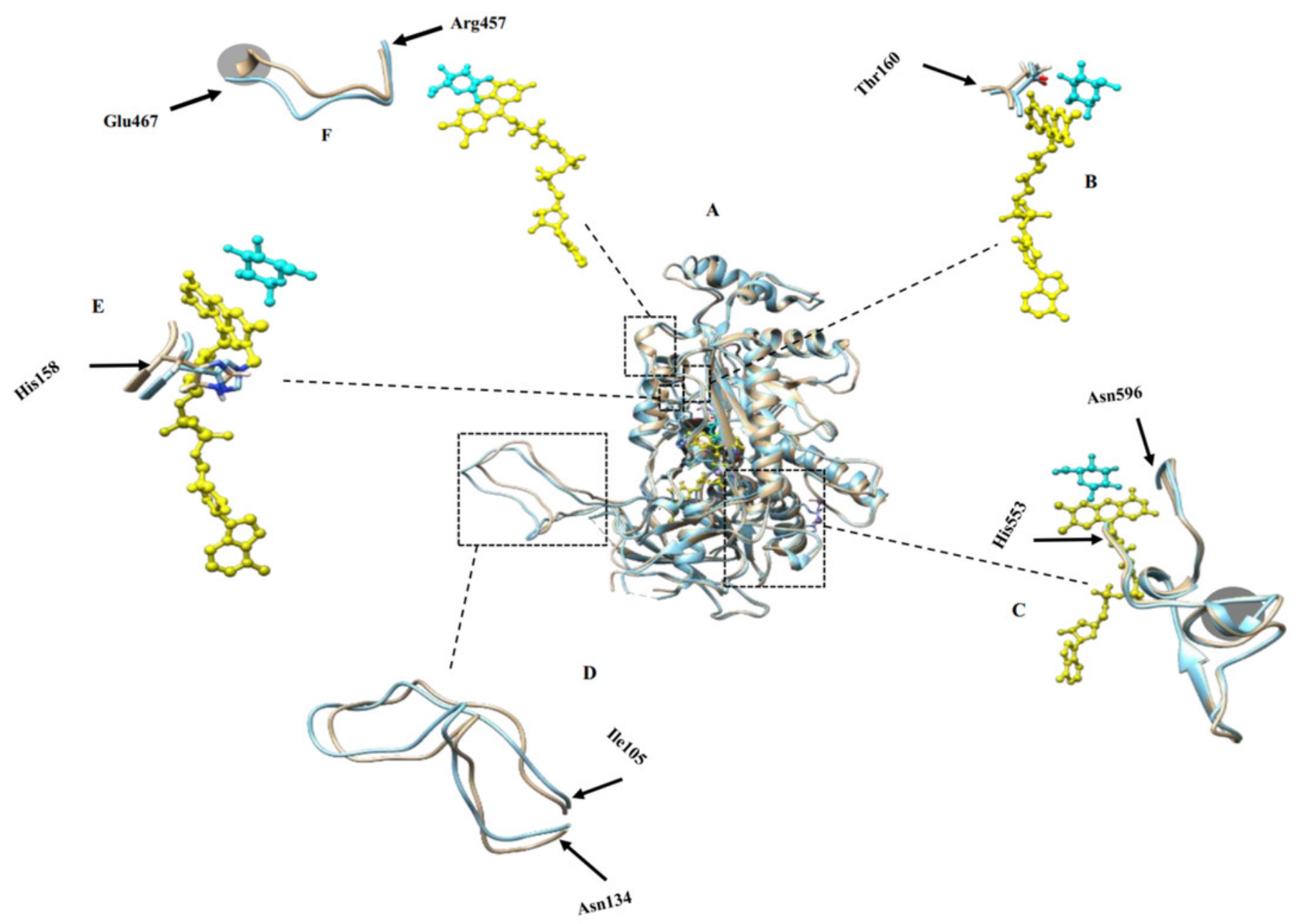


Figure 3

SDS-polyacrylamide gel ( $12 \%$ acrylamide) shows time-course of the limited proteolysis of POx by trypsin $(50: 1 \mathrm{w} / \mathrm{w})$.

(a) Molecular mass standards (lane 1); full-length POx (lane 2); POx treated with trypsin for different time points: $3 \mathrm{~min}$ (lane 3), $10 \mathrm{~min}$ (lane 4), $30 \mathrm{~min}$ (lane 5), $60 \mathrm{~min}$ (lane 6); (b) Molar mass standards (lane 1); POx treated with trypsin for different time points: $4 \mathrm{hr}$ (lane 2), $5 \mathrm{hr}$ (lane 3), $5.5 \mathrm{hr}$ (lane 4), $6 \mathrm{hr}$ (lane 5), $6.5 \mathrm{hr}$ (lane 6), $7 \mathrm{hr}$ (lane 7); full-length POx (lane 8). Arrowheads indicate standard proteins, arrows indicate POx (full-length and fragments). 

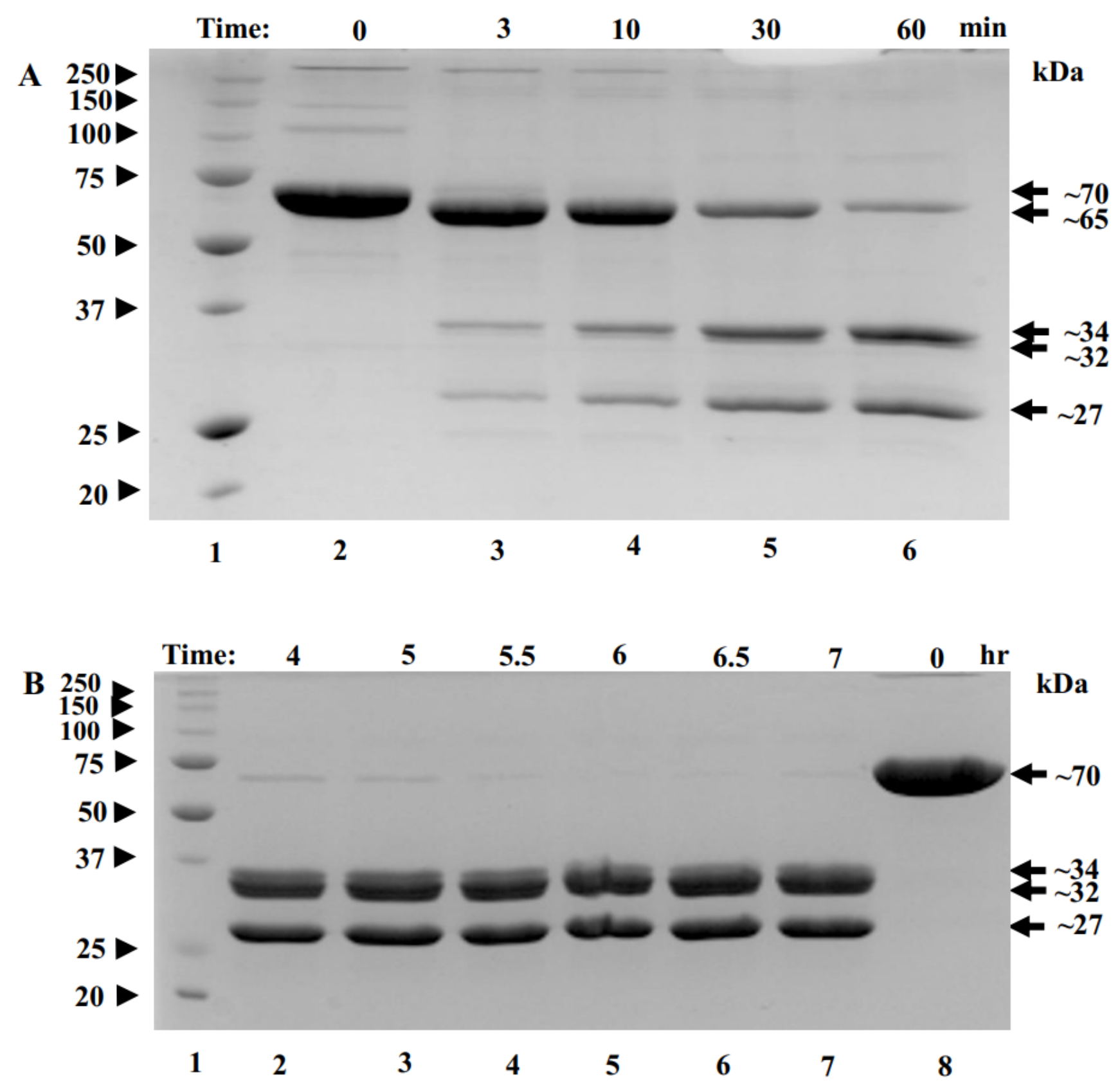


\section{Figure 4}

Results of crosslinking of POx by glutaraldehyde (GA) shown by SDS-polyacrylamide gel electrophoresis.

(A) Time dependence of crosslinking full-length POx by $0.02 \%$ GA: molecular mass standards (lane 1); full-length POx (lane 2), full-length POx treated for 10 min (lane 3) or for $60 \mathrm{~min}$ (lane 4). (B) Time dependence of crosslinking POx after $5.5 \mathrm{~h}$ of trypsinolysis by 0.05 or $0.1 \%$ of GA: molecular mass standards (lane 1); proteolyzed POx (lane 2) proteolyzed POx treated for 30 min with $0.05 \%$ (lane 3) or $0.1 \%$ GA (lane 4), and for 60 min with $0.1 \%$ (lane 5 ) or $0.05 \%$ GA (lane 6). Arrowheads indicate molecular mass standard proteins, arrows indicate cross-linked polypeptides. 


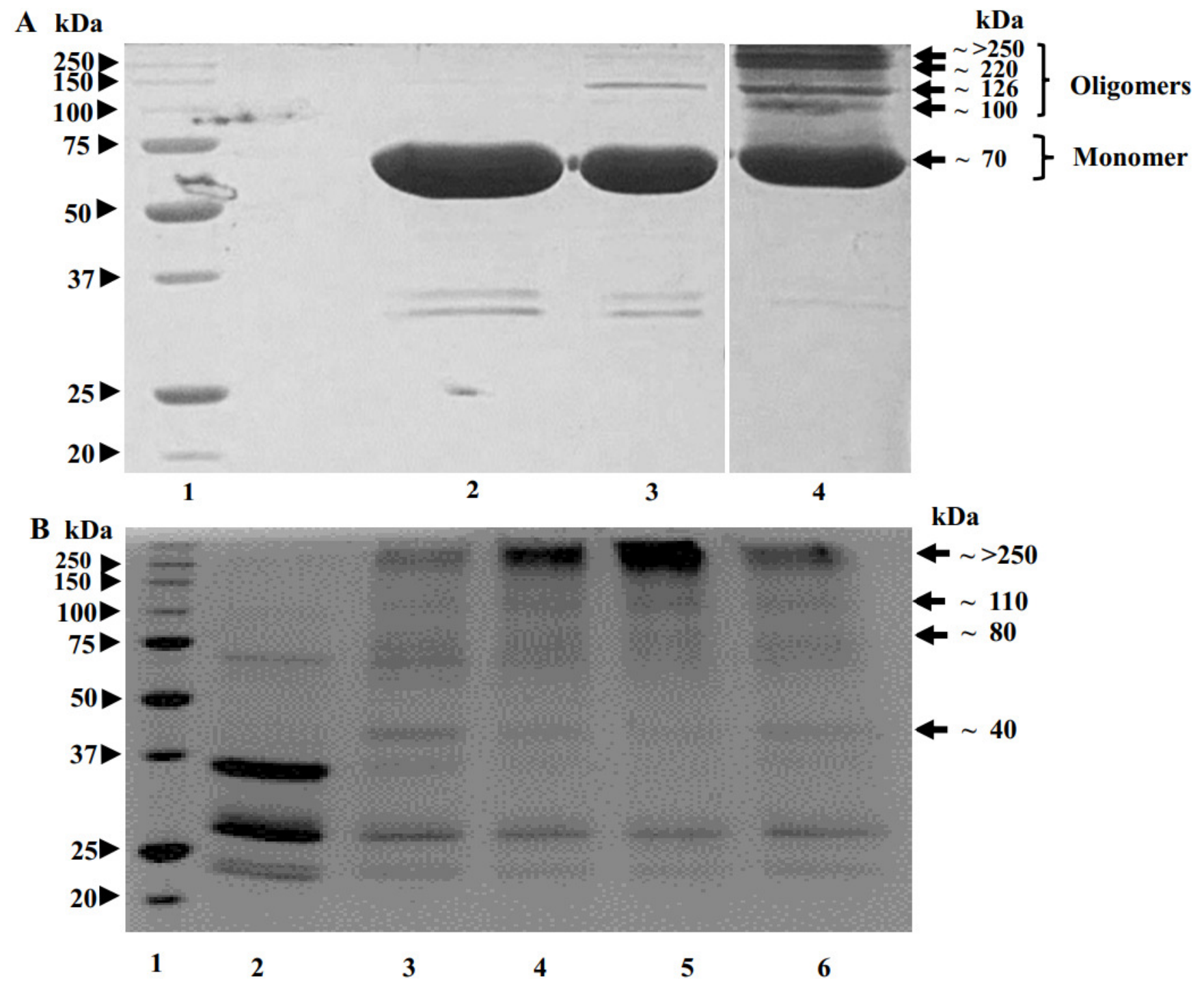


Figure 5

Figure 5. Elution profiles for dextran blue, full-length POx, proteolyzed POx after $5.5 \mathrm{~h}$ of trypsinolysis, and tropomodulin ( $40 \mathrm{kDa}$ ) obtained using size exclusion chromatography. Note, that elution profiles overlap for full-length and proteolyzed POx.

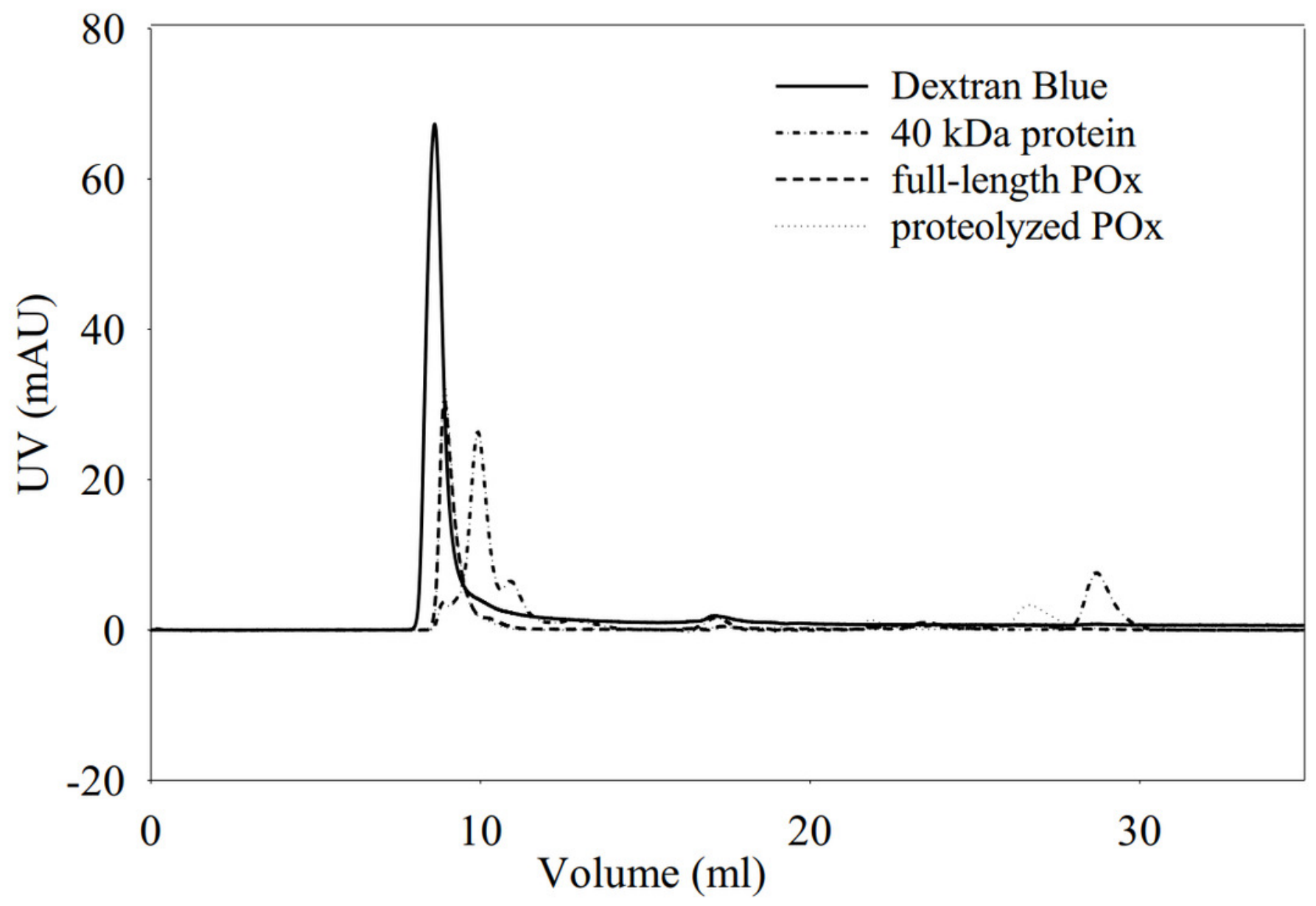


Figure 6

CD spectra measured for full-length and proteolyzed POx (after 5.5 hours of trypsinolysis) in $12.5 \mathrm{mM}$ sodium phosphate buffer, $\mathrm{pH} \mathrm{7,} 125 \mathrm{mM} \mathrm{NaCl}$. 


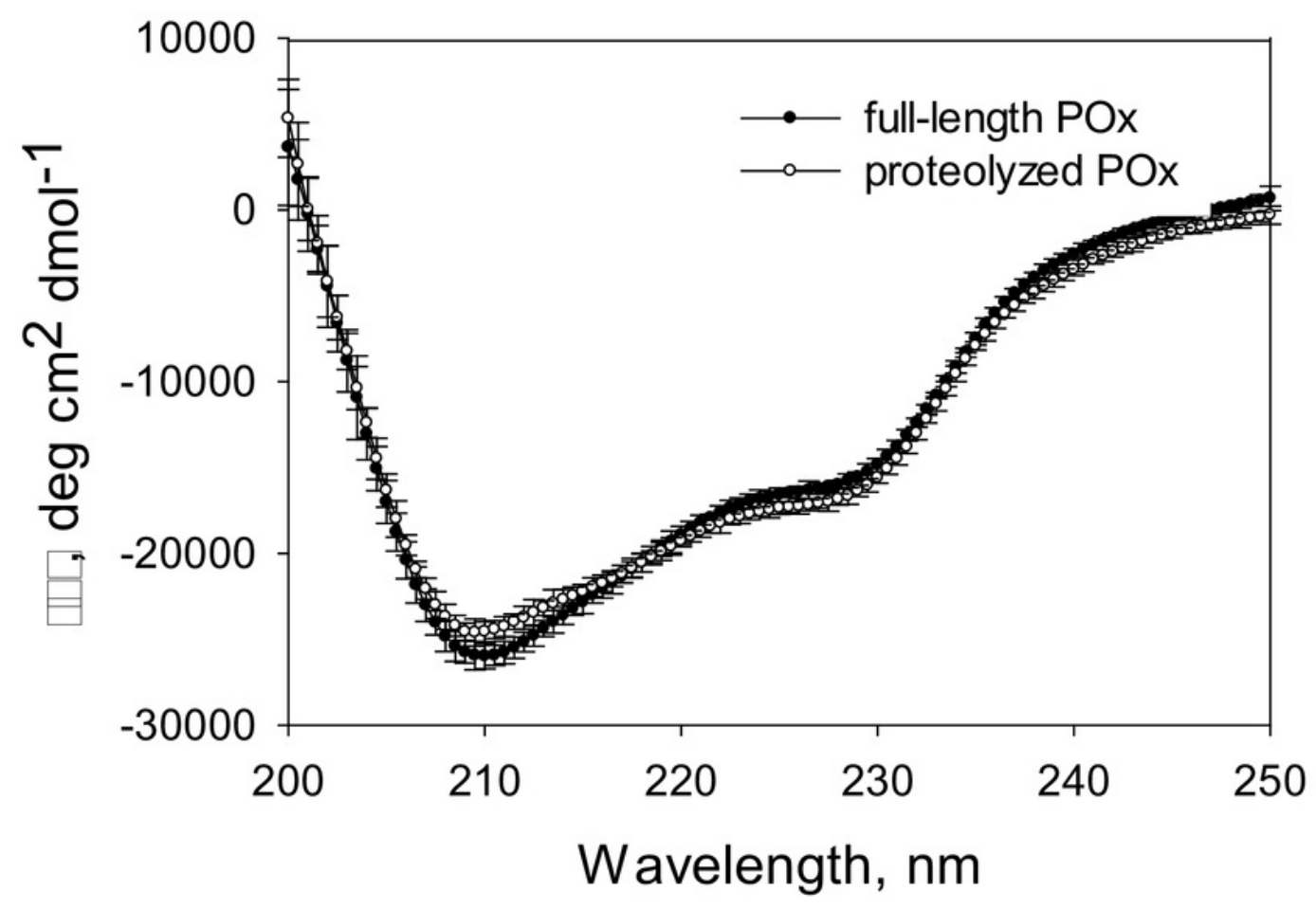

1 
Figure 7

Enzymatic activity measured for full-length and proteolyzed POx (after 5.5 hours of trypsinolysis) shows that about $90 \%$ of the activity is retained after proteolysis.

The error bars represent the standard deviation $(n=30)$.

50

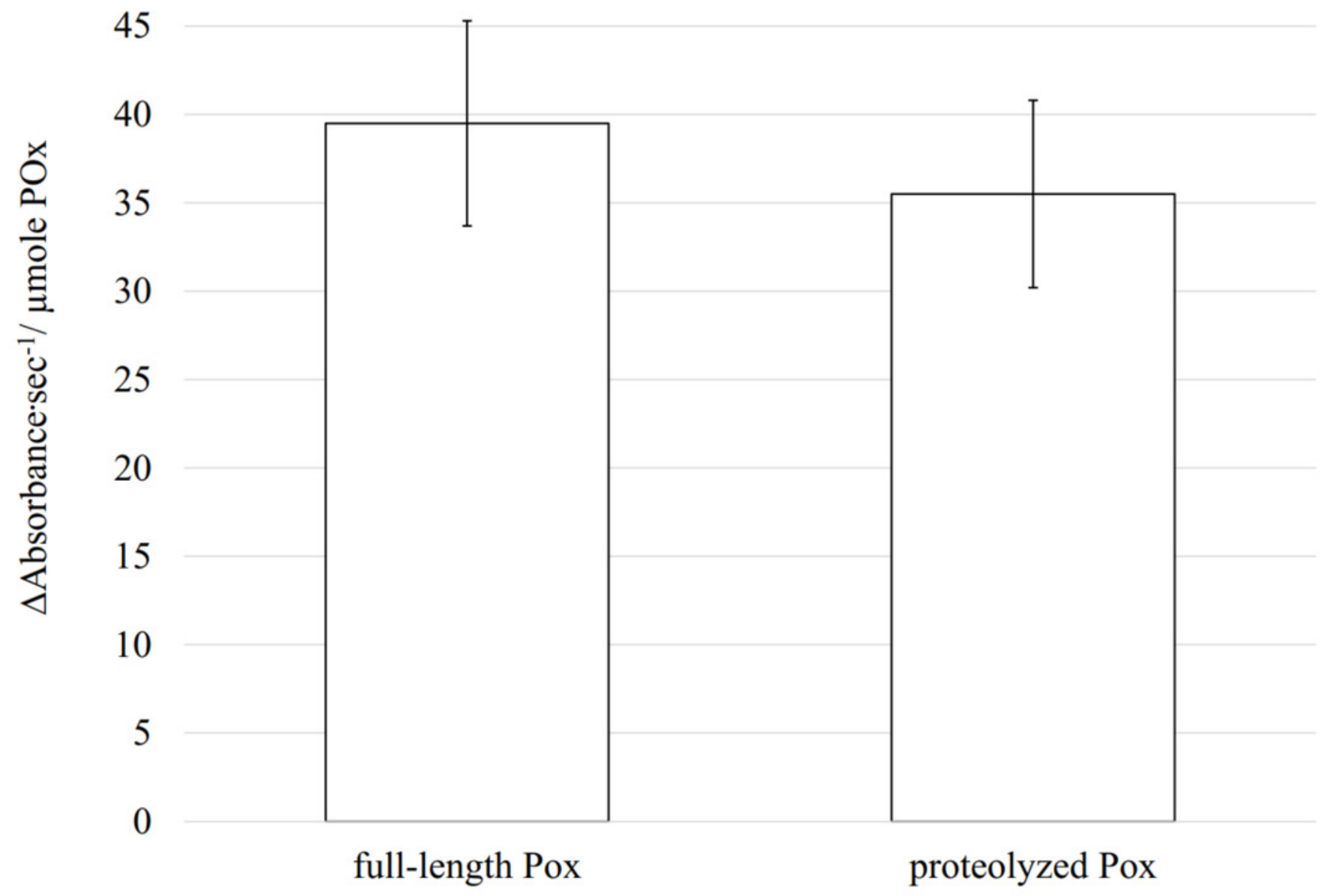

